\title{
Awareness of vitamin D deficiency among at-risk patients
}

Esubalew Alemu ${ }^{1 *}$ and Robert Varnam ${ }^{2}$

\begin{abstract}
Background: Vitamin D deficiency is a significant problem for a growing proportion of the UK population. Individuals with dark or covered skin are at particularly high risk due to ethno-cultural, environmental and genetic factors. We assessed the level of awareness of vitamin D deficiency among at-risk patients in order to identify groups most in need of education.
\end{abstract}

Findings: A cross-sectional survey using a piloted questionnaire was conducted among consecutive at-risk patients without a diagnosis of Vitamin D deficiency arriving at a large inner city general practice in the North West of England over a five day period. The survey was completed by 221 patients. The mean age was 35 years. 28\% of them $(n=61)$ had never heard about vitamin D. Older patients $(p=0.003)$ were less likely to have heard about vitamin D. $54 \%$ of participants were unaware of the commonest symptoms of vitamin D deficiency. 34\% did not expose their skin other than their face in the last one year, and $11 \%$ did not include vitamin D rich foods in their diet.

Conclusion: The majority of at-risk patients are aware of vitamin D; nevertheless, there is a significant lack of knowledge among older people, who have higher morbidity. A programme of targeted education of the at-risk population is recommended.

\section{Background}

Understanding of the role of vitamin D has been evolving since its discovery in the early 20 th century from being a simple vitamin to a steroid pro-hormone. It has been recognised to be involved in various immune functions as well as bone and muscle development [1]. Vitamin D deficiency has been reported to be linked to depression, [2] autism, [3] type 1 diabetes, [4] Syndrome $\mathrm{X},[5]$ as well as chronic widespread muscle and bone pain [6]. In infancy, it is associated with Rickets and hypocalcaemic fits $[7,8]$.

On the other hand, the current evidence shows that wearing concealing clothes is associated with Vitamin D deficiency irrespective of race or strength of solar radiation [9-11]. Other studies reported higher incidence of Vitamin D deficiency among dark skinned patients due to decreased endogenous Vitamin D synthesis coupled with ethno-cultural as well as environmental factors [12-16]. Further, in the UK, a study of multi-ethnic

\footnotetext{
* Correspondence: esubalew@doctors.org.uk

'Lancashire Teaching Hospitals, Sharoe Green Lane, Preston PR2 9HT, UK

Full list of author information is available at the end of the article
}

patients from Birmingham revealed vitamin D deficiency prevalence of 1 in 4 Afro-Caribbeans and 1 in 3 Asians compared to 1 in 8 Caucasians [17].

Moreover, studies from Tunisia, New Zealand and the United States reported insufficient Vitamin D status in $47.6 \%, 54 \%$ and $100 \%$ of their participants respectively [18-20]. Other researchers documented that the prevalence of serum 25(OH)D levels of $<25 \mathrm{nmol} / \mathrm{l}$ was 9.3 times higher in Sri Lankans living in Norway compared with those in Sri Lanka [21]. Therefore, this data suggest that migration to northern latitudes, where there is lesser sun light, confers increased risk of developing vitamin D deficiency. Hence, ethno-cultural, environmental and genetic factors appear to increase the risk of Vitamin D deficiency among the population who cover their skin or have dark skin.

As regards awareness of patients, Kung et al. conducted a telephone interview of randomly selected Chinese women in Hong Kong about vitamin D knowledge and behaviour related to sunlight. The survey showed that among 547 participants, $62.3 \%$ did not like being exposed in the sun and the majority had heard about
C Biomed Central 
vitamin D despite low level of awareness of sources and role of vitamin D [22]. Likewise, Brand et al. conducted a qualitative exploratory study of 34 immigrants in Australia and reported the existence of limitations, variations between men and women as well as age differences in knowing about vitamin D deficiency [23]. Nevertheless, this study focused on the East Africans; therefore, it cannot be generalised for the rest of dark skinned community who could have different cultural norms. Thus, further studies incorporating wider range of dark skinned participants appear necessary.

In the UK, particularly in inner city areas, a significant minority of the population are at high risk of Vitamin D deficiency, as a result of latitude, dark skin and the wearing of dress such as the hijab and burka. In Rusholme, inner city part of Manchester, approximately, $33.7 \%$ of its population $(n=16,172)$ are from ethnic minorities with dark skin whilst about $47.7 \%(\mathrm{n}=2,927)$ of these being female who are more likely to cover up [24].

Without adequate appreciation of their at-risk status, and knowledge about lifestyle modifications which can prevent Vitamin D deficiency, this portion of the population are likely to continue to suffer morbidity from musculoskeletal pain and an increased risk of Rickets and infant fits.

\section{Aims}

To ascertain the level of knowledge about Vitamin D deficiency in at risk people in an inner city area of the UK.

\section{Methods}

A face-to-face survey was conducted of a sample of patients judged to be at risk of Vitamin D deficiency by virtue of their skin colour or clothing. This was done as part of a review of patient education for patients diagnosed with Vitamin D deficiency at an inner city GP practice in Manchester. This is an audit conducted following an approval by the clinical governance lead of the practice; hence, no external ethical approval was needed.

A survey tool was developed with reference to the literature on common risk factors for deficiency and measures of patient awareness and belief likely to influence relevant aspects of lifestyle. The survey thus assessed patients' ability to avoid Vitamin D deficiency. Its face validity was refined in a two stage pilot involving face to face interviews with 43 patients, resulting in the removal of some items and the rewording of others. The initial and final tools are shown in Table 1 and Table 2. Additional file 1: contains the questionnaire used in this survey.

Every registered patient visiting the practice over a five day period from 1st of June 2009 to 5th of June 2009 was approached in the waiting room if they were of dark-skinned ethnicity or wearing garments providing total or near total skin coverage. Participants were consented and given the option of completing the survey on their own or with assistance such as reading the questions.

A data matrix was produced from the completed questionnaires using the SPSS 16.0 software. Variables for each question on the questionnaire were defined and entered according to their identification number on the SPSS Data Editor and analysed. The Chi Square Test was applied for comparing proportions and the $T$ Test for mean differences and $p<0.05$ was considered as statistically significant. Also used in the analysis process was the Microsoft Office Excel 2003. The calculated numbers were rounded off to the nearest whole number.

\section{Findings Participants}

A total of 363 patients over the age of 18 years were approached and 293 (81\%) of them participated. Seventy-two (25\%) were excluded because they already had a diagnosis of Vitamin D deficiency, leaving 221 responses for analysis.

The mean age of these was 35 with Ninety-five (43\%) of the respondents being women. Male participants

Table 1 This table lists the questions of the initial questionnaire

\begin{tabular}{ll}
\hline 1. & Have you ever had vitamin D deficiency? \\
\hline 2. & Do you take vitamin D supplements? \\
\hline 3. & Do you include vitamin D rich foods such as milk, fish oil or eggs in your meal? \\
\hline 5. & Have you done sunbathing within the last year whenever possible with exposed face, arms or legs? \\
\hline 6. & Do you know that vitamin D deficiency causes tiredness, low mood and muscle and bone pain? \\
\hline 7. & Where did you hear about vitamin D deficiency? \\
\hline 9. & Which sex are you? (If you are male, please go to Q9) \\
\hline 10. & Are you pregnant or breast feeding? \\
\hline
\end{tabular}


Table 2 This table list the questions of the final questionnaire

\begin{tabular}{ll}
\hline 1. & Have you ever heard of Vitamin D? (If you answered 'No', please go to Q9) \\
\hline 3. & Do you think vitamin D is important for your health? \\
\hline 4. & Have you ever been told that you have vitamin D deficiency (not enough vitamin D)? \\
\hline 5. & Do you take vitamin D supplements (tablets)? \\
\hline 6. & Do you include vitamin D rich foods such as milk, fish oil or eggs in your meal? \\
\hline 8. & Have you been out in the sun within the last year with exposed face, arms or legs whenever possible? \\
\hline 9. & Do you know that vitamin D deficiency causes tiredness, low mood as well as muscle and bone pain? \\
\hline 10. & Where did you hear about vitamin D? \\
\hline 11. & Which sex are you? (If you are male, please go to Q11) \\
\hline 12. & What is your age? \\
\hline
\end{tabular}

were significantly older than females (mean age 37 vs 32 respectively, $p=0.004$ ).

Respondents' level of awareness of Vitamin D and their responses regarding lifestyle risk factors are summarised in Table 3.

\section{Knowledge about vitamin D}

One hundred-sixty participants (72\%) had heard about Vitamin D, leaving 61 (28\%) who had never heard about it prior to completing the survey. Greater proportion of men than women had not heard about Vitamin D (33\% and $21 \%$ 'never heard' respectively). However, this is not statistically significant $(p=0.069)$. Those who had not heard about Vitamin D were significantly older (mean age 38 vs $33, p=0.024$ )

\section{Symptoms}

Eighty-six respondents (54\%) were unaware of the symptoms of Vitamin D deficiency. $45 \%$ and $61 \%$ of women and men respectively were not aware of the association of the symptoms with Vitamin D deficiency $(p=0.057)$. There was no age difference among those who knew the symptoms and who did not know (mean age 33, $p=$ 0.888).

\section{Diet}

A hundred and forty three participants (89\%) included Vitamin D rich foods such as milk, fish or eggs in their meals whereas $11 \%$ of them did not include any of these foods. $9 \%$ and $12 \%$ of females and males respectively did not consume these foods $(p=0.798)$. There was a small, non-significant difference in age between those who did and did not consume these foods (mean age 34 vs $30, p$ $=0.268$ ).

\section{Over-the-counter supplements}

Six percent $(n=10)$ of participants reported taking over-the-counter Vitamin D supplements. $7 \%$ of men

Table 3 This shows the number (percentage) of participants matched into categories mentioned in the table

\begin{tabular}{|c|c|c|}
\hline Details & Number (Percentage) & Remarks \\
\hline Total patients approached & $363(100 \%)$ & \\
\hline Participants & $293(81 \%)$ & \\
\hline Diagnosed with vitamin D deficiency & $72(25 \%)$ & Excluded \\
\hline Non diagnosed with vitamin D deficiency & $221(75 \%)$ & Included \\
\hline Never heard about vitamin D & $N=61(28 \%)$ & \\
\hline Heard about vitamin D & $N=160(72 \%)$ & \\
\hline \multirow[t]{2}{*}{ Know the symptoms of vitamin D deficiency? } & YES: $N=74(46 \%)$ & \\
\hline & $\mathrm{NO}: \mathrm{N}=86(54 \%)$ & \\
\hline \multirow[t]{2}{*}{ Consume milk, fish or eggs? } & YES: $N=143(89 \%)$ & \\
\hline & $\mathrm{NO}: \mathrm{N}=17(11 \%)$ & \\
\hline \multirow[t]{2}{*}{ Taking over-the-counter vitamin D supplements? } & YES: $N=10(6 \%)$ & Missing data $=1$ \\
\hline & $\mathrm{NO}: \mathrm{N}=149(94 \%)$ & \\
\hline \multirow[t]{2}{*}{ More than their face exposed in the sun? } & YES: $N=105(66 \%)$ & \\
\hline & $\mathrm{NO}: \mathrm{N}=55(34 \%)$ & \\
\hline
\end{tabular}


and $5 \%$ of women were taking the supplements. This indicates that larger proportion of men than women take supplements, nevertheless, there was no statistical significance $(p=0.752)$. Again, a small, non-significant age difference was observed between those who were and were not taking supplements (mean age 35 vs 33 respectively, $p=0.706)$. On the other hand, $6 \%(\mathrm{n}=8)$ and $12 \%(\mathrm{n}=2)$ of those who were and were not consuming Vitamin D rich foods respectively were taking Vitamin D supplements in spite of lack of statistical significance $(p=0.290)$.

\section{Exposure in the sun}

Fifty-five participants (34\%) had not exposed more than their face to the sun within the last year. The percentage of women who were not exposed to the sun was greater than that of men ( $36 \%$ vs $33 \%$ respectively). Nonetheless, this did not have statistical significance $(p=0.740)$. Those exposed in the sun were slightly younger than unexposed ones (mean age 33 vs 34 respectively, $p=$ 0.648). On the other hand, those who were not exposed in the sun were more likely to take supplements as $15 \%$ of those unexposed in the sun were taking Vitamin D supplements and only $2 \%$ of those exposed were on supplementation $(p=0.003)$.

\section{Sources of information}

One hundred-sixty participants (72\%) responded to the question regarding how they heard about Vitamin D. The results are presented in Figure 1. Family and friends were the most popular source cited by 63 participants and followed by school education [n $=45]$ and GP [n = 32]. Also mentioned were television [ $n=25]$, hospital staff $[n=17]$, the internet $[n=18]$ and leaflets $[n=17]$.

\section{Suggested ways of promoting awareness}

A hundred and twenty five respondents (57\%) suggested ways of promoting awareness among the at-risk population. The results are presented in Figure 2. The most common suggestion was use of leaflets mentioned by $52 \%$ followed by GP/Nurse consultation (15\%) and poster display (14\%). Also suggested ways include providing verbal information (12\%), advertising on media (11\%) and organising educational sessions (7\%).

\section{Discussion}

The results identify a significant unmet need for education about vitamin D among people at risk of deficiency. Nearly a third of people at risk of deficiency by virtue of dark or covered skin had never heard of it whereas just over a third were getting almost no sun exposure and very few took appropriate supplements.

On the other hand, men and older people had particularly low levels of awareness of Vitamin D deficiency and its potential consequences. Gender influences on health related attitudes and behaviour are common findings $[23,25]$. The influence of age on Vitamin D awareness confirms findings of a survey among patients in Hong Kong [22] and highlights the inaccessibility and lack of perceived relevance of much health information to the older generation.

As regards this study, since the data was collected with a questionnaire mainly comprising of closed questions, the fact gathered is limited. Moreover, individuals who turned up at the practice may be different from those who did not in relevant ways. This was a small non-random sample of residents in one UK city, albeit with a high response rate. Hence, further research is sought in order to confirm the findings.

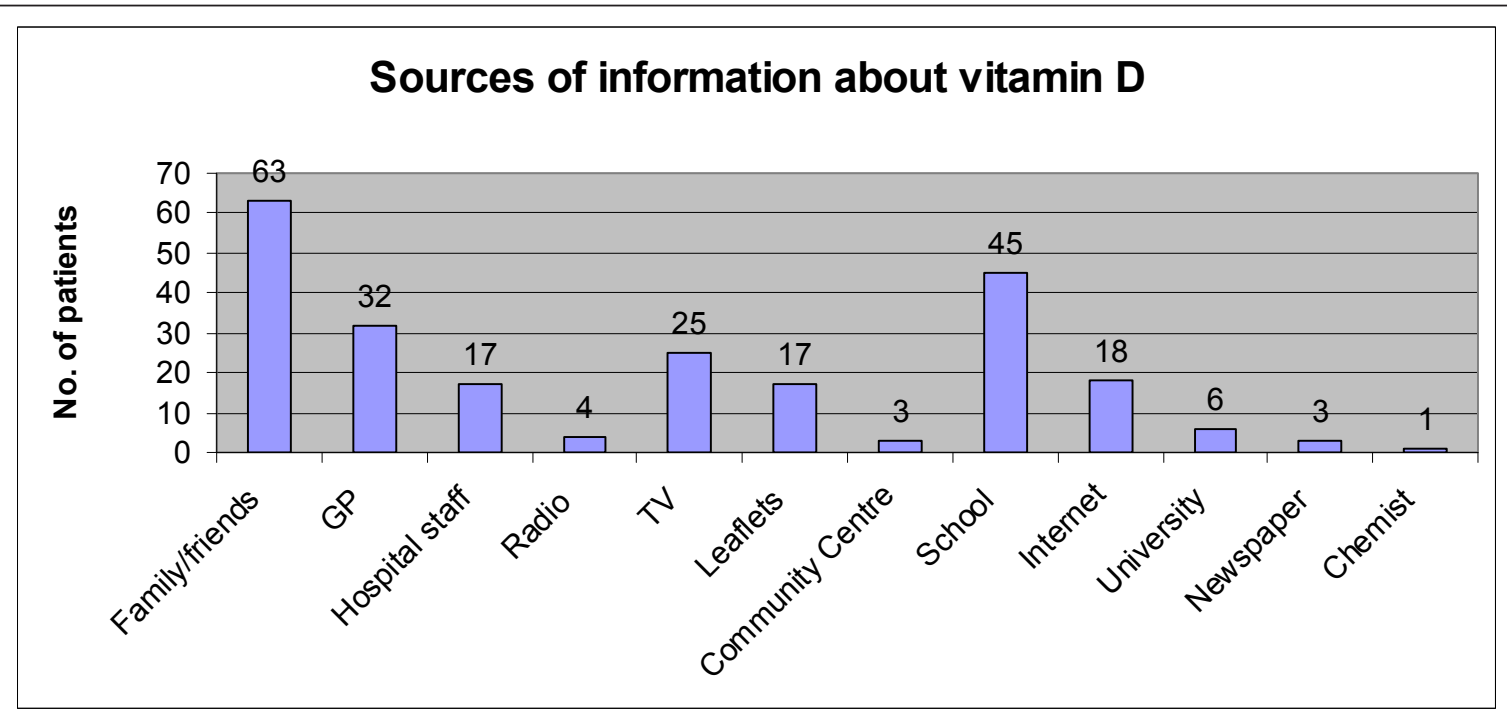

Figure 1 This shows the number of patients in relation to the ways they heard about vitamin $D$. 


\section{Suggested ways of promoting awareness}

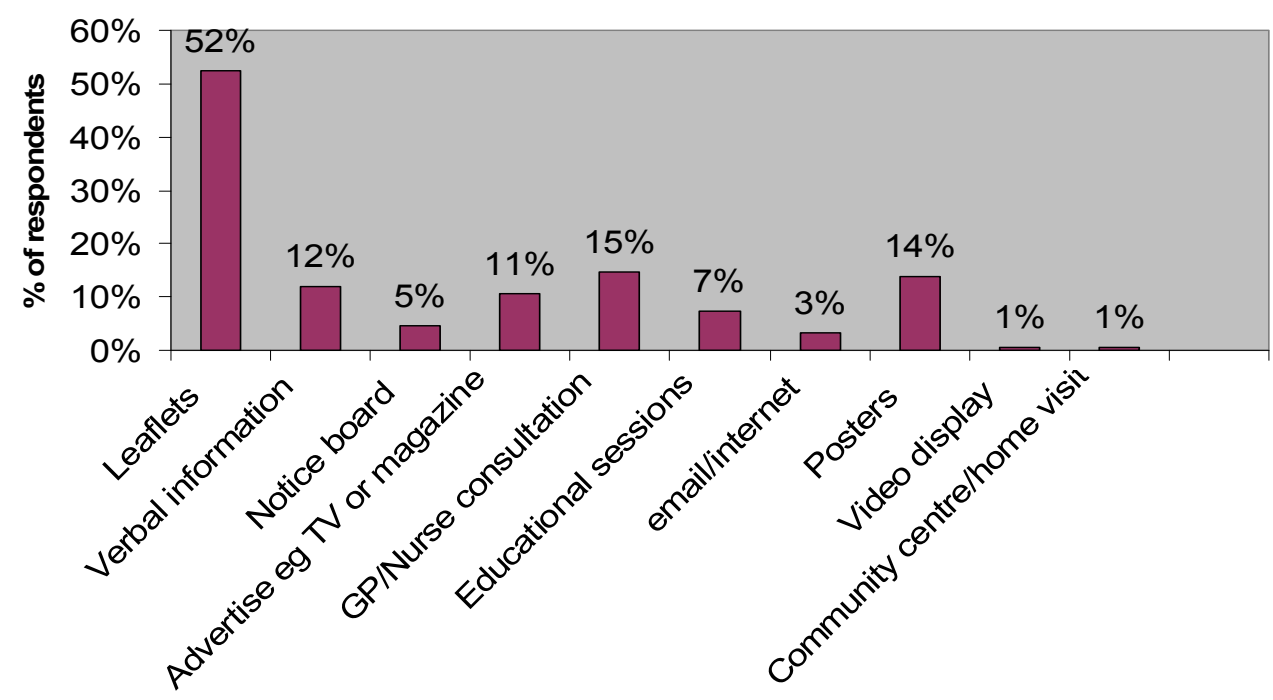

Figure 2 This shows the percentage of participants in relation to their suggestions of ways of promoting awareness.

Fresh effort is recommended to address the needs of the at risk population for education about Vitamin D deficiency and ways of avoiding it. This should address both suggested lifestyle modifications and symptoms, which warrant consultation with the GP. A third of participants had received information about Vitamin D from family or friends. While the social connections of older at-risk people may differ from this group, community networks appear to be a promising vector for the dissemination of education about this important problem. The group with greatest need for education are also more likely than the general population to consult their GP, and this may also prove an important source of education.

Recommendations to change lifestyle factors in Vitamin D deficiency may not be popular, as other work has shown [26] and the lower levels of UVB radiation received from the sun at higher latitudes may significantly limit the benefit of sun exposure in the UK. The role of the GP in offering pharmacological Vitamin D to at risk patients may therefore be paramount.

\section{Conclusion}

This study highlighted the existence of differences in awareness of Vitamin D deficiency among men and women whilst age playing a significant role. Thus, a concerted collaboration is required amongst the health care providers and others such as community members to promote the awareness and bridge this gap.

\section{Additional material}

Additional file 1: Questionnaire used for data collection.

\section{Abbreviations}

25(OH)D: 25-Hydroxyvitamin D; GP: General Practitioner.

\section{Author details}

${ }^{1}$ Lancashire Teaching Hospitals, Sharoe Green Lane, Preston PR2 9HT, UK. ${ }^{2}$ The Robert Darbishire Practice,Rusholme Health Centre, Walmer Street, Rusholme, Manchester M14 5NP, UK.

\section{Authors' contributions}

EA designed the questionnaire, approached the patients, collected the data, performed statistical analysis and drafted the manuscript.

RV supervised designing of the questionnaire, data collection and data analysis as well as editing and finalising the manuscript. All authors read and approved the final manuscript.

\section{Competing interests}

The authors declare that they have no competing interests.

Received: 27 July 2011 Accepted: 9 January 2012

Published: 9 January 2012

\section{References}

1. Deluca HF: Evolution of our understanding of vitamin D. Nutr Rev 2008, 66(10): $573-587$

2. Hoogendijk WJG, Lips P, Dik MG, Deeg DJH, Beekman ATF, Penninx BWJH: Depression Is Associated With Decreased 25-Hydroxyvitamin D and Increased Parathyroid Hormone Levels in Older Adults. Arch Gen Psych 2008, 65(5):508-512.

3. Cannell JJ: Autism and vitamin D. Med Hypoth 2008, 70(4):750-759.

4. Harris SS: Vitamin D in type 1 diabetes prevention. J Nutr 2005, 135(2):323-325. 
5. Boucher BJ: Inadequate vitamin D status: does it contribute to the disorders comprising syndrome ' $X$ '? Brit J Nutr 1998, 79(4):315-327.

6. Turner MK, Hooten WM, Schmidt JE, Kerkvliet JL, Townsend CO, Bruce BK: Prevalence and clinical correlates of vitamin $D$ inadequacy among patients with chronic pain. Pain Med 2008, 9(8):979-984

7. Ahmed I, Atiq M, lqbal J, Khurshid M, Whittaker P: Vitamin D deficiency rickets in breast-fed infants presenting with hypocalcaemic seizures. Acta paediatrica 1995, 84(8):941-942.

8. Camadoo L, Tibbott $R$, Isaza F: Maternal vitamin D deficiency associated with neonatal hypocalcaemic convulsions. Nutr J 2007, 6:23.

9. Glerup H, Mikkelsen K, Poulsen L, Hass E, Overbeck S, Thomsen J, Charles P, Eriksen EF: Commonly recommended daily intake of vitamin $D$ is not sufficient if sunlight exposure is limited. $J$ Int Med 2000, 247:260-268.

10. Gannage-Yared MH, Chamali R, Yaacoub N, Halaby G: Hypovitaminosis D in a sunny Country: Relation to Life Style and Bone Markers. J Bon and Min Res 2000, 15:1856-1862.

11. Allali F, El Aichaoui S, Saoud B, Maaroufi H, Abouqal R, Hajjaj-Hassouni N: The impact of clothing style on bone mineral density among post menopausal women in Morocco: a case-control study. BMC Public Health 2006, 6:135

12. Egan KM, Signorello LB, Munro HM, Hargreaves MK, Hollis BW, Blot WJ: Vitamin D insufficiency among African-Americans in the southeastern United States: implications for cancer disparities (United States). Can Caus \& Cont 2008, 19(5):527-35

13. Weng FL, Shults J, Leonard MB, Stallings VA, Zemel BS: Risk factors for low serum 25-hydroxyvitamin $D$ concentrations in otherwise healthy children and adolescents. Amer J Clin Nutr 2007, 86(1):150-158.

14. Serhan E, Newton P, Ali HA, Walford S, Singh BM: Prevalence of hypovitaminosis $D$ in Indo-Asian patients attending a rheumatology clinic. Bone 1999, 25(5):609-611.

15. Plotnikoff GA, Quigley JM: Prevalence of severe hypovitaminosis D in patients with persistent, nonspecific musculoskeletal pain. Mayo Clin Proceed 2003, 78(12):1463-70.

16. Rashid A, Mohammed T, Stephens WP, Warrington S, Berry JL, Mawer EB: Vitamin D state of Asians living in Pakistan. Br Med J 1983, 286(6360):182-184

17. Ford L, Graham V, Wall A, Berg J: Vitamin D concentrations in an UK inner-city multicultural outpatient population. Annal Clin Biochem 2006, 43(Pt 6):468-73.

18. Meddeb N, Sahli H, Chahed M, Abdelmoula J, Feki M, Salah H, et al: Vitamin D deficiency in Tunisia. Osteopor Internat 2005, 16(2):180-183.

19. Wishart HD, Reeve AM, Grant CC: Vitamin D deficiency in a multinational refugee population. Inter Med J 2007, 37(12):792-797.

20. Hobbs RD, Habib Z, Alromaihi D, Idi L, Parikh N, Blocki F, Rao DS: Severe vitamin $D$ deficiency in Arab-American women living in Dearborn, Michigan. Endocr Pract 2009, 15(1):35-40.

21. Meyer HE, Holvik K, Lofthus CM, Tennakoon SU: Vitamin D status in Sri Lankans living in Sri Lanka and Norway. Brit J Nutr 2008, 99(5):941-944.

22. Kung AWC, Lee KK: Knowledge of vitamin D and perceptions and attitudes toward sunlight among Chinese middle-aged and elderly women: a population survey in Hong Kong. BMC Pub Heal 2006, 6:226

23. Brand CA, Abi HY, Couch DE, Vindigni A, Wark JD: Vitamin D deficiency: a study of community beliefs among dark skinned and veiled people. In J Rheum Dis 2008, 11:15-23.

24. Manchester City council: Health Fact Sheet Rusholme., Available from: http://www.manchester.gov.uk/site/scripts/google_results.php?q=population + fact+sheet+rusholme+2007 Accessed on 12 August 2009

25. Lim WY, Ma S, Heng D, Bhalla V, Chew SK: Gender, ethnicity, health behaviour \& self-rated health in Singapore. BMC Pub Heal 2007, 7:184.

26. Stephens WP, Klimiuk PS, Warrlngton S, Taylor JL, Berry JL, Mawer EB: Observations on the Natural History of Vitamin D Deficiency amongst Asian Immigrants. Q J Med 1998, 51:171-188.

doi:10.1186/1756-0500-5-17

Cite this article as: Alemu and Varnam: Awareness of vitamin D

deficiency among at-risk patients. BMC Research Notes 2012 5:17. 